\title{
Autonarrativas no fluxo da pesquisa: operando com operações dos observadores
}

\section{Self-narratives in the flux of the research: operating with the operations of the observers}

\author{
Nize Maria Campos Pellanda ${ }^{1}$ \\ Maira Meira Pinto ${ }^{1}$
}

\begin{abstract}
RESUMO
Neste artigo, relatamos o processo de investigação, em movimento, de um grupo de pesquisa transdisciplinar, constituído de cinco projetos de pesquisa vinculados, tendo como elemento organizador o princípio de convergência, e, como eixo de convergência, o tema Educação e Complexidade. A ênfase, aqui, é dada às autonarrativas dos membros do grupo, que se constituem em dispositivos metodológicos de uma epistemologia complexa, considerando-se a necessidade de inclusão do observador na realidade observada. Neste sentido, o que estamos fazendo com estas práticas é dar conta das operações dos próprios operadores, exercendo os pressupostos de segunda ordem advindos da Segunda Cibernética.
\end{abstract}

Palavras-chave: epistemologia da complexidade; autonarrativas; observador e observado.

\footnotetext{
ABSTRACT

In the present article we describe an investigation process, which has been developed by a transdisciplinary research group, consisting of five linked research projects, having as an organizing element the convergence principle

DOI: $10.1590 / 0104-4060.41109$

1 Universidade de Santa Cruz do Sul. Santa Cruz do Sul, Rio Grande do Sul, Brasil. Av. Independência, nº 2293. CEP: 96815-900. Pesquisadora colaboradora da UMINHO (Portugal). E-mail: nizepe@uol.com.br; Pesquisadora e Coordenadora do Curso de Serviço Social. E-mail:
} mmeirapinto@gmail.com 
and the topic of Education and Complexity as the axis of convergence. The emphasis is given to the self-narratives of the group members which are constituted by methodological tools with a complex epistemology, considering the necessity of including the observer in the observed reality. In this sense, what we are doing with these practices is to report the transactions of the operators themselves, exercising the assumptions of second order, arising out of Second Cybernetics.

Keywords: complexity epistemology; self-narratives; observer and observed.

"Investiguei a mim mesmo."

Heráclito (Frag. 101)

\section{Introdução}

Abordaremos neste texto práticas narrativas de pesquisadores e bolsistas num grupo de pesquisa. Trata-se de um grupo de investigações transdisciplinares que inclui pesquisadores das áreas de educação, psicologia, epistemologia, comunicação e letras, numa abordagem complexa que privilegia os isomorfismos, os processos e os fluxos. Um denominador comum dos diferentes projetos vinculados é a inseparabilidade conhecer/subjetivar-se e a inclusão do observador nos sistemas observados. O eixo teórico do projeto de pesquisa ${ }^{2}$ é Educação e Complexidade e o princípio organizador é a convergência.

O paradigma da complexidade está libertando a ciência do profundo esfacelamento ao qual foi submetida pela modernidade. A tarefa é resgatar a ciência e a cultura, atualmente limitadora, pois a realidade é una em todas as suas dimensões. Isso é o que tem nos ensinado a sabedoria perene desde o pensamento oriental integrador e holístico até as pesquisas da Física Quântica, bem como as recentes descobertas das neurociências, termodinâmica, biologia da complexidade, dentre outras. O movimento cibernético contribuiu decisivamente para esta transição paradigmática ao trazer as questões de sistema e processo. Bateson (2000a), um dos primeiros e mais brilhantes membros do grupo dos ciberneticistas, alertava para os perigos de uma epistemologia racionalista e reducionista. Dizia ele: "Creio que os primeiros passos epistemológicos de

2 Projeto transdisciplinar desenvolvido na Universidade de Santa Cruz do Sul. Setor de Educação. Santa Cruz do Sul, Rio Grande do Sul, Brasil. Av. Independência, nº 2293, CEP: 96815-900. 
Descartes - a separação de espírito e matéria e o cogito - estabeleceram más premissas e, quem sabe, em última instância, premissas letais para a epistemologia [...]." (BATESON, 2000a, p. 33).

Ainda no século XVII e, portanto, contemporâneo de Descartes, Espinosa falava numa Substância Única, expressando a ideia de uma realidade profundamente imbricada, em que os afectos são responsáveis pelas emergências do viver, incluindo o conhecer como a capacidade de ser afectado. (ESPINOSA, 1983). Pairando sobre todo o nosso trabalho está a ideia integradora de Morin (1991, p. 91): “complexus é aquilo que se tece junto", bem como suas reflexões sobre a complexidade da realidade.

Nessa perspectiva e, a partir do eixo complexidade, usamos o princípio teórico da convergência para entendermos como os fenômenos vão se entrelaçando no fluxo de nossas vidas. Usamos o princípio da convergência de Teilhard de Chardin, que o torna inseparável do processo de complexificação da realidade ao explicitar a ideia de que subir (complexificar) é convergir. (TEILHARD DE CHARDIN, 1974). Teilhard (1974) defende isso num contexto de complexidade para formular sua lei da complexificação/consciência.

As ideias que acabamos de propor fazem parte de um novo paradigma que desafia a ciência clássica, trazendo para a arena científica a investigação de si, a metodologia da primeira pessoa e a preocupação com a inclusão do observador no sistema observado como consequência destas integrações. E mais, o que importa agora é dar conta de forma concreta do sofrimento resultante de subjetividades esfaceladas como resultado de um longo processo cultural que marcou a modernidade. Resgatando o introspeccionismo de William James, tão esquecido em tempos de positivismo, o que interessa realmente para os seres humanos é o que conta para a vida concreta, o que realmente funciona, deixando de lado todas as abstrações estéreis. (JAMES, 1979).

Nesses termos, investigamos no nosso grupo de pesquisa a questão da construção do conhecimento como inseparável da constituição subjetiva do sujeito epistêmico, que não é um sujeito universal, como pregava Piaget (1983), mas um sujeito singular e concreto que produz diferença como condição básica para o seu viver. Por perpassar todos os projetos vinculados, usamos as autonarrativas como instrumento metodológico complexo. Elas são elaboradas por cada pesquisador(a) e por cada bolsista de Iniciação Científica e são discutidas nas reuniões semanais do grupo, resultando em atividades metacognitivas, pois são momentos em que refletimos sobre o nosso próprio processo de pesquisa.

O que pretendemos com este artigo é fazer um relato de uma experiência em primeira pessoa, explicitando como estas atitudes são constituintes da construção de conhecimento no grupo, de forma inseparável da transformação 
subjetiva de cada um(a) de nós. Lembramos mais uma vez Teilhard (1974), neste ponto, para nos dar sustentação teórica:

$\mathrm{O}$ objeto e o sujeito se mesclam e se transformam mutuamente no ato do conhecimento. Queiramos ou não, a partir deste momento, o homem encontra a si mesmo e se contempla em tudo o que observa. (TEILHARD DE CHARDIN, 1974, p. 44).

Deste relato e com base em alguns excertos das escritas dos membros do grupo, pretendemos chegar a inferências mais amplas sobre a inseparabilidade do processo de conhecer/autoconstituir-se e mais focais, como o papel das autonarrativas neste fluxo. O projeto de convergência do grupo é a "Construção do conceito de ontoepistemogênese". A questão central deste projeto vinculado é construir um conceito que dê conta da inseparabilidade ser/conhecer. Para isso, então, cunhamos o termo ontoepistemogênese e estamos trabalhando pela sua construção teórico-conceitual.

\section{A vida como processo cognitivo}

"Conhecer é viver. Viver é conhecer." H. Maturana e F. Varela

Foi com este espírito de pragmatismo e de complexidade e ancorados no movimento cibernético, principalmente na sua fase de fenômenos de segunda ordem, que começamos a investigar as questões da inseparabilidade de conhecer e subjetivar-se. Entendemos como fenômenos de segunda ordem aqueles que implicam em uma lógica de recursividade subjetiva, em que o observador implicado se apropria de seus próprios processos, tais como: conhecer como se conhece, aprender a aprender, mudar na mudança e, acrescentaríamos, ainda, observar o observador.

Para perseguir os objetivos de nosso projeto de pesquisa, procuramos nos sustentar teoricamente nos pressupostos desenvolvidos por Heinz von Foerster na Segunda Cibernética, bem como nas teorias que aplicaram, na prática da pesquisa, os pressupostos foersterianos. É o caso de Henri Atlan, com sua teoria da "Complexificação pelo Ruído" (1992), e o H. Maturana e F. Varela, com a 
"Biologia da Cognição" (1980). Em todos os estudos destes investigadores está presente, como marca cibernética, o princípio da auto-organização. A presença funcional deste princípio no funcionamento da vida é concretizada pelos princípios complementares da "ordem pelo ruído", que Von Foerster formulou e que Atlan deu forma em sua teoria da complexificação pelo ruído e pelo conceito de autopoiesis, desenvolvido por Maturana e Varela. O conceito de autopoiesis é o eixo central da teoria desenvolvida por Maturana e Varela. Eles cunharam este conceito para explicar o funcionamento dos seres vivos como autoprodutores de si mesmos. As teorias biológicas desenvolvidas por estes cientistas são teorias complexas, pelo fato de não separarem o conhecer do viver.

A epistemóloga portuguesa Clara da Costa Oliveira, situada nesta matriz teórica que estamos referindo, assume seu lugar no Movimento de Auto-Organização (MAO), defendendo o “[...] estudo sistemático e profundo sobre o modo como se constituem as narrativas individuais". (OLIVEIRA, 2007, p. 166). Ela destaca a dimensão narrativa das histórias de vida como o que existe de mais estrutural nos atos humanos. (OLIVEIRA, 2007).

Abordar esses fenômenos subjetivos implica na adoção de uma metodologia complexa que inclua o observador, que ainda não foi cartografada, mesmo que reconheçamos que muitos esforços significativos e consistentes estejam sendo realizados atualmente, por isso, consideramos o método narrativo desenvolvido por Clara Oliveira muito importante neste processo de construção. Para proceder a esta cartografia, então, nos debruçamos profundamente nos estudos da cibernética para buscar pressupostos, visando à construção de uma epistemologia complexa que pudesse dar suporte nesta presente tarefa. Neste sentido, começamos pelas ideias do próprio Von Foerster, G. Bateson e F. Varela.

Von Foerster tem um papel importantíssimo na história da ciência em geral e nos rumos do movimento cibernético, em particular ao propor uma passagem dos sistemas observados para os sistemas observantes. Com isso, ele inaugura uma segunda fase do movimento, conhecido como a Segunda Cibernética. Não é mais, portanto, um pesquisador observando, de fora, uma realidade, mas ele tem que dar conta de suas próprias operações. $\mathrm{O}$ autor expressa isso muito bem nas palavras: "Esta tarefa clama por uma epistemologia do 'Como nós conhecemos' em vez de 'O que conhecemos"”. (von FOERSTER, 1974, p. 248).

Bateson mostra com muita lucidez que "[...] não existe uma clara demarcação entre epistemologia e ontologia". (BATESON, 2000a, p. 32). Von Foerster foi muito influenciado por Bateson, que teve um lugar destacado no movimento, como já referido, desde as primeiras conferências cibernéticas. A contribuição lógica deste cientista foi fundamental, ajudando a configurar uma nova epistemologia mais condizente com os novos pressupostos paradigmáticos. Foi ele quem destacou o papel da abdução ao enfatizar a importância dos isomorfismos 
e das metáforas, que ajudam a articular as diferentes dimensões da realidade, enfrentando, portanto, a fragmentação da tradição newtoniana-cartesiana e ultrapassando os movimentos de mão única da indução ou da dedução. Daí a complexidade da obra batesoniana. E foi exatamente o que Bateson passou sua vida fazendo, juntando o que foi separado, ao propor uma lógica abdutiva como suporte de uma metodologia que ele chamava de ecológica, num sentido ampliado. Para Bateson (2000b), quanto mais evoluímos na complexidade da aprendizagem mais refinada será nossa "ecologia da mente", na medida em que vamos nos ligando, cada vez mais, ao cosmos.

Nesse trabalho de articulações profundas, Bateson traz o "si mesmo", a "autoconstrução" e até mesmo o sagrado para o campo da investigação, chegando a propor que evolução e aprendizagem são a mesma coisa ao mostrar que ambos os fenômenos são produtores de diferenças. Os seres humanos sobrevivem e se transformam porque são produtores de diferença, num movimento em que a auto-organização é fundante. O princípio de auto-organização do ser vivo, no que diz respeito à sua construção subjetiva, está relacionado à capacidade que tem de ultrapassar sempre níveis de aprendizagem, em direção a outros mais complexos. Passamos para um nível mais complexo de aprendizagem quando somos capazes de olhar o que aprendemos de um ponto de vista observacional. Esta complexificação está ligada, portanto, à capacidade auto-organizativa de superar o mais indiferenciado pela criação de significado para a vida de um indivíduo. (BATESON, 2000a). No fundo deste processo está o fenômeno da reversão da entropia, graças à capacidade de transformar a ordem através da construção de sentido vital.

Varela tenta sistematizar, com base no princípio da auto-organização e da concepção de sistemas vivos com clausura operacional, uma metodologia de primeira pessoa. (VARELA, 1974). Quando fizemos referência à necessidade de dar conta das operações do próprio observador, estamos pensando na questão de tratar a experiência pessoal dos sujeitos envolvidos, seja na pesquisa, seja no próprio ato de conhecer, em geral. A ciência da modernidade nos ensinou a falar sempre na terceira pessoa para descrever um mundo que estaria fora de nós e com o qual mantemos uma suposta relação de neutralidade. Tudo se passa como se não fôssemos coautores da realidade que vivemos e autores de nossa própria vida. A complexidade dos fenômenos de segunda ordem nos alerta para esta falácia de exclusão do sujeito cognitivo/ontológico. Varela (1974) é um dos mais entusiasmados críticos desta atitude. Diz ele: 
uma relação com coisas lá-fora de maneira independente dos conteúdos mentais-aqui-dentro. (VARELA, 1974, p. 296).

O importante é pensar esta nova epistemologia em termos de emergências, de fluxos e de processos, pois a experiência não é constituída de conteúdos pré-existentes, mas ela se dá no bojo do processo de participação num sistema. Isto não quer dizer, como nos alerta Varela (1974), que seja uma investigação menos rigorosa que uma investigação em terceira pessoa. O que ele defende é não deixar de fora a experiência do ser humano, que constrói a si mesmo ao construir a realidade.

\section{Narrativa como instrumento de auto-organização}

"De que mais mesmo se pode falar a não ser de si mesmo?"

Heinz von Foerster

Como descrito nas palavras anteriores, a auto-organização é o princípio de funcionamento da vida, considerada aqui como um sistema fechado de acordo com a teoria da Biologia da Cognição. (MATURANA; VARELA, 1980). Este fato nos leva a pensar em mecanismos auto-organizativos, que garantem a passagem de estados de indiferenciação para estados de construção de diferença, ou singulares e, portanto, portadores de significados para a vida. Neste processo, que é explicado pelo princípio de Von Foerster da "ordem pelo ruído", a entropia vai sendo revertida, o que aumenta a ordem interna do sistema. Todos estes fenômenos compõem um sistema que vai se complexificando. A auto-organização cria mais caos (ruído), que vai sendo transformado em mais ordem, o que, por sua vez, cria novos ruídos e, assim, segue-se o processo vital numa espiral, cada vez mais complexa. O motor desta complexificação é o papel do observador situado no interior do sistema. Como resultado deste operar, surgem emergências que são constituintes do sistema. Caracterizamos este processo de complexificação.

Nossas atividades no grupo de pesquisa estão pautadas na autoexperimentação. Nesta perspectiva, instrumentos de auto-organização, como a autonarrativa, por exemplo, podem ajudar os sujeitos narradores de si a se organizar, construindo novos sentidos para a sua vida e, portanto, a se complexificar. As autonarrativas funcionam como perturbações constantes. 
São momentos muito dinâmicos para que os pesquisadores(as) possam se experimentar, o tempo todo, em seu devir subjetivo e cognitivo. A proposta é a de que sejam produzidas autonarrativas sobre o processo de viver neste grupo, focando não nos conteúdos formais da pesquisa, mas em como o que vai sendo estudado e vivido "bate" neles(as) em termos de perturbações. Para Maturana (1999), conhecer não é representação ou captação de uma realidade externa. Ele afirma, ao contrário, que os seres vivos são fechados à informação e abertos para a troca de energia. Neste sentido, somos os criadores de nós mesmos e o que vem de fora apenas nos perturba e não nos determina. (MATURANA, 1999). Assim, os membros do grupo vão pensando sobre si mesmos, se auto-organizando através das narrativas em exercícios metacognitivos, nos quais podem refletir sobre seus próprios processos, apropriando-se deles autopoieticamente.

É importante acrescentar aqui que todas as sessões são gravadas e que procedemos sistematicamente à audição e à degravação destes registros que, por sua vez, foram objeto de estudo deste artigo. Além disto, todos(as) os(as) pesquisadores(as) produzem suas autonarrativas com uma determinada periodicidade como forma de exercitar seu autoconhecimento e para dar (mais) visibilidade àquilo que estamos produzindo no grupo e como isto está relacionado à ontoepistemogênese.

Na sequência, destacamos alguns trechos das escritas dos sujeitos/ pesquisadores(as) em que podemos identificar padrões auto-organizativos e complexificantes, que emergiram no bojo do trabalho com as autonarrrativas. Entendemos complexificação aqui, reforçando o que já foi referido, como a capacidade de fazer relações cada vez mais intrincadas entre dimensões diferentes da realidade e em relação a si mesmo, como também, ainda, a emergência de padrões, a partir da ação. No fundo, há um claro processo de constituição de si através da linguagem.

Em coerência com a metodologia complexa adotada e em construção, esclarecemos que não usamos categorias de análise que engessam a abordagem de uma realidade viva em devir. Aplicamos marcadores no sentido de sinalizar o que emerge no fluxo dinâmico de uma realidade sempre em trânsito. Assim, selecionamos para análise do material aqui apresentado os marcadores "complexificação" e "percepção de autopoiesis".

Alguns excertos das autonarrativas do grupo:

Sujeito/pesquisador 1:

Será que as autonarrativas podem ser apresentadas em forma de diário? Como não tenho muito tempo para escrever, então, é interessante anotar 
o dia e o espaço no qual se produziu algum pensamento mais sistemático ou uma vaga ideia do que me "perturbou", intelectualmente... Mesmo que seja uma espécie de "fotografia" mental, com o aspecto de arrefecida, quando no papel, ao ser lida, a linguagem torna-se viva!

Aqui podemos perceber claramente o ruído inicial dado por atitudes perturbatórias. A partir do ruído, o sujeito/pesquisador vai se organizando depois de passar por uma desconstrução. Neste processo, vai se complexificando, pois vai aprendendo a trabalhar com as emergências e construindo novos sentidos para a sua vida ao fazer novas questões. Para Bergson (1979), conhecer é inventar questões. Neste movimento, o sujeito vai se apropriando de sua própria linguagem de forma viva e metacognitiva.

Sujeito/pesquisador 2:

Como percebo meu processo autopoiético no processo da pesquisa: Ao assumir posturas mais autônomas, colocando em prática o que foi aprendido (vivenciar conceitos aprendidos). Nas reuniões do nosso grupo, quando nos emocionamos durante as interações e passamos a aplicar isso em nossa vida diária, nas relações interpessoais. Ao assumir o controle de meu barco, sabendo que sou um ser virtual que se autoproduz o tempo todo, que não posso contar com o externo, a não ser pelas perturbações (emoções). Ler Nietzsche foi vital para mim e para perceber a importância do conceito de potencia.

Nesta narrativa fica bem expressa a presença dos dois marcadores selecionados para a leitura dos textos dos pesquisadores: complexificação e percepção de autopoiesis. Há a compreensão de que autonomia é autoconstituição e o entendimento complexo de que aprender é pôr em prática, isto é, viver o aprendido. Importante também nesta autonarrativa é o uso de metáforas de forma abdutiva com inferências sobre a virtualidade do ser como potência. Neste trecho também podemos captar o quanto o narrador se apropriou da filosofia espinosiana tão debatida no grupo, no sentido de entender as emoções como parte integrante do conhecer. 
Sujeito/pesquisador 3:

Tenho aprendido muito com este grupo ao longo destes últimos anos. Cada um(a) de vocês me perturba de alguma forma me mostrando o próprio processo em termos de uma complexificação. Tenho percebido na vivência pessoal profunda o que são emergências e o que significa viver no fluxo. Acho que entendi no grupo aquilo que Maturana quer dizer com as palavras: "Viver não custa nada. O que custa é lutar contra a vida".

Novamente, neste relato, temos a presença da complexificação no sentido da auto-organização, a partir do ruído. Uma aguda percepção do que significa viver no fluxo e do conceito de emergência a ele ligado. Destaca-se aqui a presença do pensamento abdutivo, como sustentação para o pensamento complexo.

Sujeito/pesquisador 4:

Sobre as questões teóricas, a vivência no Grupo me permitiu uma postura mais reflexiva e despida de preconceitos. Sempre me inquieta a questão das tecnologias, no sentido de melhor compreender, tantos recursos necessários, mas o quê fazemos com tudo isso? O que passa pelas mentes que recebem toda essa informação? Qual o sentido de tanta tecnologia? Entendam que não questiono a importância, usufruo e gosto muito das ferramentas disponibilizadas. A minha inquietação é no sentido de investigar que dispositivos movem as pessoas a se configurarem ou reconfigurarem a partir da tecnologia.

Neste fragmento autonarrativo surge uma questão complexa em relação às tecnologias, que é objeto de um dos projetos vinculados. Este sujeito fez uma elaboração complexa, no sentido de entender 'tecnologia' como acoplamento sujeito/máquina constituindo o devir dos seres humanos e não como algo que está fora dos sujeitos. Neste sentido, fez uma elaboração cognitivo/ontológica sobre a tecnologia como configuradora dos seres humanos. Esta autonarrativa lembra muito as reflexões de Teilhard de Chardin, que pensou a técnica numa perspectiva cósmica e, portanto, complexa. Ele referia que o mundo emerge do movimento cósmico, não sendo apenas uma peça, sendo acrescentada ao mundo. $\mathrm{O}$ cultural, seria, então, o natural hominizado, referindo-se à organização da matéria em companhia do psiquismo. (TEILHARD DE CHARDIN, 2011). 
Sujeito/pesquisador 5:

\begin{abstract}
Depois do Grupo as coisas começaram a mudar rapidamente, passei a observar minhas ações, sentimentos, pensamentos, identificar o que eles traziam de bom e de ruim para minha vida e a partir disso perceber quais são os próximos passos. Essa prática é complicada porque muitas vezes nosso humor ou a rotina não nos deixa tempo para pensar nas questões do ser, mas eu me considero uma pessoa de ciclos, isto se dá de uma forma misteriosa e fora de uma lógica, alguns acontecimentos me fazem pensar mais sobre mim e como me construo, por vezes passei mais de uma semana introspectivo organizando meus pensamentos e tentando entender como tenho aprendido e de que maneira o conhecimento interfere na minha vida. De uma maneira mais sintética, procuro sempre lembrar que tudo o que acontece à minha volta interfere no que sou, e a partir disso procurar entender como esse conhecimento chega a mim e como estou assimilando cada acontecimento.
\end{abstract}

Nesta autonarrativa observamos o processo de complexificação de maneira genética, ou seja, o sujeito vai fundo na genealogia de si mesmo, investigando como foi se constituindo e distinguindo, claramente, o papel do conhecimento no processo. Ele pratica uma auto-observação, que é circular e emergente, pois, ao fazer isso, ele se reconstrói e surgem fenômenos que são novos para ele. É interessante notar neste fragmento a intuição de como os hábitos fazem nossa vida. Tanto a filosofia oriental, principalmente através dos Yogues, como as neurociências hoje, mostram que a maior parte das vezes agimos com pouca autonomia, levados pelos hábitos. Sob o ponto de vista neurofisiológico, os impulsos tendem a percorrer os mesmos caminhos em função do reforço das sinapses envolvidas, configurando, então, o que chamamos um hábito e os padrões predominantes de nosso pensar. Tomar consciência de nossos hábitos aumenta nossa autonomia e, portanto, nossa capacidade autopoiética.

Em todos os fragmentos notamos um nítido processo de complexificação marcado pelo modo de lidar com as emergências, com a capacidade abdutiva de inventar metáforas sobre o viver e a autopercepção de mudança de níveis de complexificação. O que subjaz a estas ideias é a noção organizadora de que não existe uma realidade prévia às nossas ações. A vida e o conhecimento só acontecem com nossa ação efetiva sobre o mundo e sobre nós mesmos.

O que precisa ser destacado nas autonarrativas é a presença de elementos de segunda ordem: o pensar sobre o próprio processo, repensando-se nesta atitude e reconfigurando-se ao pensar em alternativas. Outros elementos de segunda 
ordem aqui presentes são: aprender a aprender, mudar na mudança e observar o próprio observador. Todas estas são atitudes que potencializam os sujeitos, pois eles se tornam mais autônomos ao mudar hábitos arraigados, com maior apropriação de si mesmos.

No entanto, o que gostaríamos de destacar com maior ênfase é a percepção da inseparabilidade ser/conhecer, pois é nosso objeto central de pesquisa no grupo de investigação ao qual pertencemos. Para expressar este fenômeno complexo do viver cunhamos o conceito de ontoepistemogênese, já referido anteriormente, com a intenção de abordar o ser humano de forma integrada, articulando todas as dimensões do viver. Este ainda é um conceito em construção. Estamos realizando sistematizações de elaborações emergentes no grupo tentando dar ao conceito uma estrutura lógica. Por este motivo, ainda não explicitamos aqui os detalhes deste processo.

\section{Considerações finais}

Uma das primeiras inferências que podemos fazer sobre as narrativas descritas é a implicação de outro nível de pensamento lógico - a abdução - no sentido em que não foram do geral para o particular (dedução), nem do particular para o geral (indução), mas os sujeitos trabalharam no sentido de juntar dimensões psíquicas e cognitivas, fazendo disparar a ação que emergia, sob a forma de autoproposição de alternativas de vida e de invenção de novos sentidos. Para Peirce (1975), a abdução está relacionada com a inteligência em movimento, a percepção do fluxo vital. Tudo isso se constitui num claro processo de complexificação dos sujeitos narradores e na percepção de que somos os autores da nossa vida que vai se fazendo no movimento do devir.

Nesse devir, a vida de cada um de nós vai se configurando com nossas ações, hábitos e pensamentos, pois não nascemos prontos. E, autopoieticamente, precisamos nos construir no fluxo do viver ao mesmo tempo em que construímos cognição. Um instrumento poderoso de constituição de conhecimento/ realidade é a narrativa, portanto. Somos seres de linguagem e o humano, como sempre afirma Maturana, se constitui na linguagem. E, dentro da linguagem, a narrativa é instrumento poderoso de constituição de si, na medida em que é um instrumento complexo, pois leva os sujeitos a perceber a emergência do conhecer e do ser de forma inextrincável.

Somos aquilo que narramos de nós mesmos e, ao fazermos isso, nos complexificamos no sentido de maior autonomia e, portanto, de autoria de nós 
mesmos. As pesquisas em andamento no grupo foram se articulando de maneira complexa com a subjetivação dos participantes, de tal forma que cognição e subjetivação, num processo inseparável, mostram a presença de uma lógica circular, rompendo com a linearidade causa-efeito. O que vimos nestas autonarrativas pode ser ilustrado através das palavras de Connely e Candinin (1995):

A razão principal para o uso da narrativa na investigação educativa é que os seres humanos são organismos contadores de histórias, organismos que, individual e socialmente, vivem vidas relatadas. $\mathrm{O}$ estudo da narrativa, portanto, é o estudo da forma na qual nós, os seres humanos, experimentamos o mundo. (CONNELY; CANDININ, 1995, p. 11).

Para finalizar, queremos resgatar a ideia de Maturana de que o que importa agora não é mais perguntar: O que é isso? Mas sim: como faço para conhecer isso? (MATURANA; PORKSEN, 2004). Esta noção corresponde a uma postura de segunda ordem expressa por Von Foerster, sobre a mudança do conhecer para como conhecer (Von FOERSTER, 1974). Estas questões nos levam, necessariamente, a um conhecimento genético num sentido tal que temos que atentar para como se produz este processo cognitivo e como nos constituímos nele como self. Foi isso o que tentamos fazer ao longo de todo o trabalho de abordagem das narrativas analisadas.

\section{REFERÊNCIAS}

ATLAN, Henri. Entre o cristal e a fumaça. Rio de Janeiro: Zahar, 1992.

BATESON, Gregory. Steps to an ecology of mind. Chicago: The University of Chicago Press, 2000a.

BATESON, Gregory. El temor de los angeles. Barcelona: GEDISA, $2000 \mathrm{~b}$.

BERGSON, Henri. O pensamento e o movente. São Paulo: Abril, 1979.

CONNELY, Michael; CLANDININ, Jean. Relatos de experiência e Investigación narrativa. In: LARROSA, J. et al. Déjame que te cuente. Barcelona: Laertes, 1995.

ESPINOSA, B. Ética. São Paulo: Abril Cultural, 1983.

JAMES, William. Pragmatismo. São Paulo: Abril, 1979. 
MORIN, Edgar. Introdução ao pensamento complexo. Lisboa: Instituto Piaget, 1991. MATURANA, Humberto. Transformaciones. Santiago: Dólmen, 1999.

MATURANA, Humberto; PORKSEN, Bernard. Del ser al hacer. Santiago: J.C. Saez, 2004.

MATURANA, Humberto; VARELA, Francisco. Biology and Cognition. London: Reidel, 1980.

OLIVEIRA, Clara Costa. Contributos educativos e comunitários do movimento epistemológica da auto-organização - Um método auto-organizativo na formação de educadores de adultos. Revista Educação, v. 61, p. 165-180, 2007. Disponível em: <http://revistaseletronicas.pucrs.br/ojs/index.php/faced/article/view/545/381>. Acesso em: 31 maio 2014.

PEIRCE, Charles Sanders. Semiótica e Filosofia. São Paulo: Cultrix, 1975.

PIAGET, Jean. Epistemologia Genética. São Paulo: Abril, 1983.

TEILHARD DE CHARDIN, Pierre. El fenómeno humano. Madrid: Taurus, 1974. Disponível em: <http://eugematil.vilabol.uol.com.br/alfa.htm>. Acesso em: 25 fev. 2011.

VARELA, Francisco. El fenómeno de la vida. Santiago: Dolmen, 1974.

Von FOERSTER, Heinz. Understanding Understanding. New York: Springer, 1974.

Texto recebido em 28 de abril de 2015. Texto aprovado em 25 de agosto de 2015. 